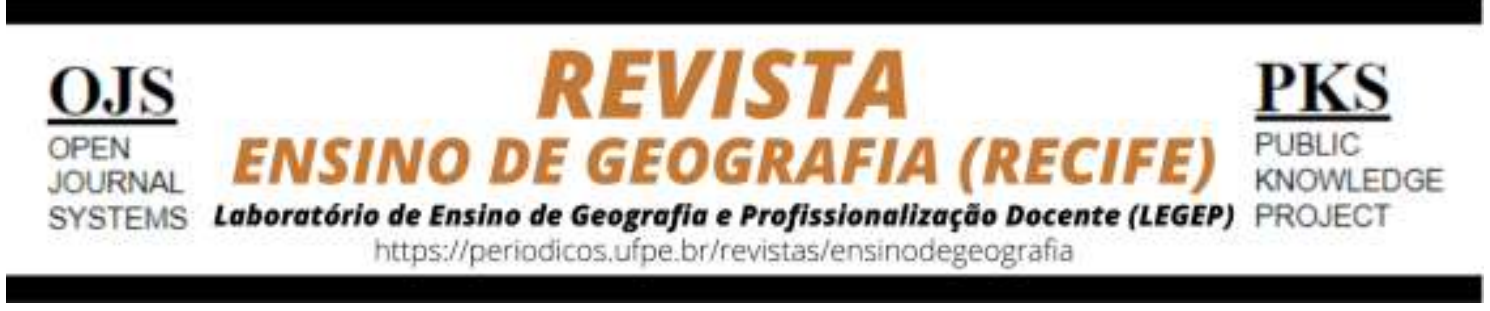

\title{
O ESTÁGIO PARA A FORMAÇÃO DO PROFESSOR- PESQUISADOR EM GEOGRAFIA COM ENFOQUE NA EDUCAÇÃO AMBIENTAL
}

\author{
Letícia Ramires Corrêa ${ }^{1}$, Tuane Telles Rodrigues ${ }^{2}$
}

1 Graduada em Geografia pela UFSM. Mestra em Geografia pelo PPGGEO-UFSM. Doutoranda pelo PPGGeo-UFSM. Professora da rede municipal de Vila Nova do Sul. E-mail: leticiarcorrea@gmail.com ORCID iD: http://orcid.org/0000-0002-7372-3141

${ }^{2}$ Graduada em Geografia pela Universidade Federal de Santa Maria-UFSM e mestre em geografia pelo Programa de Pós-graduação em Geografia-PPGGEO/UFSM. Doutoranda em geografia pelo PPGGEO/UFSM. E-mail: tuanytel@hotmail.com - ORCID iD: http://orcid.org/0000-0003-0747-6004

Artigo recebido em 17/11/2019 e aceito em 01/04/2020

\begin{abstract}
RESUMO
Este trabalho objetiva discutir as contribuições do estágio para a formação do professor/pesquisador em Geografia com enfoque na Educação Ambiental (EA) a partir da socialização das experiências vivenciadas no Estágio Curricular Supervisionado Obrigatório e no Estágio Extracurricular, vinculados ao curso de Licenciatura em Geografia e ao Curso de Pós-Graduação em Geografia (PPGGeo) da Universidade Federal de Santa Maria (UFSM). Os estágios foram realizados em diferentes instituições de ensino e pesquisa, sendo: uma escola de nível fundamental e outra de nível médio do município de Itaara/RS; a Fundação MO' $\tilde{A}$ (Santa Maria/RS); o Centro de Estudos de Geografia e Ordenamento Territorial (CEGOT); e o Laboratório da Paisagem (Portugal). As atividades experienciadas nestas instituições permitiram que se realizassem pertinentes discussões e reflexões sobre a importância dos estágios na formação do professor/pesquisador em Geografia, uma vez que se amplia a leitura e interpretação do pensamento geográfico em diferentes contextos físicos e sociais.
\end{abstract}

Palavras-chave: Geografia; Educação Ambiental; formação docente.

\section{THE STAGE FOR TEACHER / RESEARCHER TRAINING IN GEOGRAPHY WITH A FOCUS ON ENVIRONMENTAL EDUCATION}

\begin{abstract}
This work aims to discuss the contributions of the internship to the formation of the teacher / researcher in Geography with a focus on Environmental Education (EA) from the socialization of the experiences lived in the Supervised Compulsory Curricular Internship and the Extracurricular Internship, linked to the Geography and Licentiate Degree course. to the Postgraduate Course in Geography (PPGGeo) at the Federal University of Santa Maria (UFSM). The internships were carried out in different teaching and research institutions, as follows: one elementary school and one secondary school in the city of Itaara / RS; the MO'ÂA Foundation (Santa Maria / RS); the Center for the Study of Geography and Spatial Planning (CEGOT); and the Landscape Laboratory (Portugal). The activities experienced in these institutions allowed pertinent discussions and reflections to be carried out on the importance of internships in the formation of the teacher / researcher in Geography, since the reading and interpretation of geographic thinking in different physical and social contexts is broadened.
\end{abstract}

Keywords: Geography; Environmental education; teacher training. 


\section{Introdução}

O estágio é um momento importante na vida de um profissional no âmbito da aplicação e no aprimoramento do conhecimento adquirido durante sua formação. Este aperfeiçoamento conceitual e prático tende a refletir-se tanto no ensino, na formação docente, quanto nas atividades relacionadas à pesquisa.

A importância do estágio vem sendo discutida amplamente, já que a prática se configura como parte sensível na formação dos professores/pesquisadores e, por conseguinte, reflete-se na qualificação educacional como um todo. Dessa forma, a experiência possibilita ao formando o estudo aprofundado tanto no âmbito físico e social Geográfico, como também no aperfeiçoamento das relações interpessoais ocorridas em diferentes contextos culturais no qual ele se insere.

No Ensino de Geografia, o estágio permite o aperfeiçoamento da didática e o melhor domínio dos conteúdos fundamentais da ciência geográfica. Em função disso, e com a busca por novos métodos que possibilitem a aprendizagem significativa dos discentes, a qualificação do ensino se empodera. Entretanto, um dos maiores desafios do estágio está na mediação entre o conhecimento científico e os saberes dos alunos que, por sua vez, têm a necessidade de aplicar este conhecimento rotineiramente, dando-lhe significado.

Assim sendo, o presente artigo traz como objetivo central discutir a relevância do estágio para a Educação Ambiental em duas modalidades; o Curricular Supervisionado Obrigatório, pré-requisito para a formação acadêmica; e o Estágio Extracurricular, em que o pesquisar solicita a permanência na instituição para aperfeiçoar-se enquanto professor e pesquisador. Dessa forma, as discussões se embasam nas experiências adquiridas em diferentes instituições no período entre 2016 e 2019, sendo elas: a Escola Municipal de Ensino Fundamental Alfredo Lenhardt e a Escola Estadual de Ensino Médio de Itaara, ambas localizadas no município de Itaara, Rio Grande do Sul, Brasil; a Fundação MO``̃ ${ }^{1}$, localizada no município de Santa Maria, também no Rio Grande do Sul; no Centro de Estudos de Geografia e Ordenamento Territorial ${ }^{2}$ (CEGOT), e no Laboratório da Paisagem (Portugal) ${ }^{3}$.

\footnotetext{
${ }^{1}$ Organização não-governamental (ONG) de estudos e pesquisas para o desenvolvimento e proteção ambiental atua desde 1996 a partir de pesquisas e educação ambiental na região central do Rio Grande do Sul.

${ }^{2}$ Centro de estudos da Universidade do Minho (Portugal)

${ }^{3}$ Associação para a promoção do desenvolvimento sustentável promove o conhecimento e a inovação, a investigação e a divulgação científica junto ao Conselho de Guimarães (Portugal).
} 


\section{Discussões teóricas}

A grande preocupação do professor de Geografia é formar cidadãos críticos e observadores do espaço, compreensivos do meio em que vivem, valorizando sua cidade, seu bairro e as pessoas que ali vivem, bem como as relações advindas das interações sociais e com o meio ambiente. Apesar disso, muitos docentes em formação podem deparar-se com instituições em que as demandas dos discentes decorrem de um sistema de ensino pouco dinâmico ou, por vezes, desconectado da realidade dos próprios alunos. Em função disso, devem-se aproximar os conhecimentos científicos dos saberes dos alunos e de suas realidades. Esse descolamento entre o conhecimento sobre múltiplos acontecimentos nacionais e internacionais em contraste com as poucas discussões sobre o conhecimento do lugar, tema esse já discutido por Callai (1988), pode ser uma das primeiras barreiras enfrentadas pelos futuros professores de Geografia durante o estágio.

Ao aprofundarmos nos problemas de nossa época, somos levados a perceber que eles não podem ser entendidos isoladamente. São problemas sistêmicos, o que significa dizer que estão interligados e são interdependentes (CAPRA, 1996), ou seja, quando falamos de problemas ambientais engloba-se os sociais, que por sua vez são consequências de tal modelo econômico que rotula valores para tudo que existe, natural ou artificial.

Para a realização do estágio curricular supervisionado obrigatório busca-se métodos para o Ensino de Geografia, de maneira que os alunos possam construir a partir de seus saberes uma educação crítica, capazes de ler o mundo em diferentes linguagens, ver além do que é exposto e construir de forma dialética uma sociedade para o futuro.

$\mathrm{Na}$ área da Educação Ambiental, a contemporaneidade exige que as conexões discursivas sejam convergentes entre os recursos do lugar, a antropinização local, e as políticas nacionais e internacionais sobre a conservação e preservação dos recursos naturais. Dessa forma, tais problemas e soluções adquirem cada vez mais importância no diálogo com a comunidade local. De acordo com o Art. $1^{\circ}$, da Lei ${ }^{\circ} 9.795$, de 27 de abril de 1999, entende-se por EA:

Os processos por meio dos quais o indivíduo e a coletividade constroem valores sociais, conhecimentos, habilidades, atitudes e competências voltadas para a conservação do meio ambiente, bem de uso comum do povo, essencial à sadia qualidade de vida e sua sustentabilidade. 
Os Parâmetros Curriculares Nacionais de Geografia, vinham desde 1997 tendo a Educação Ambiental (chamada de Meio Ambiente). Assim, os PCN's (1997, p.46) dizem que:

A compreensão das questões ambientais pressupõe um trabalho interdisciplinar. A análise de problemas ambientais envolve questões políticas, históricas, econômicas, ecológicas, geográficas, enfim, envolve processos variados, portanto, não seria possível compreendê-los e explicá-los pelo olhar de uma única ciência.

O mundo para o aluno é muitas vezes o "lugar" em que vivem, construído a partir das relações do cotidiano, nesse sentido o Ensino de Geografia apropria-se de tal conceito, dando sentido aos conteúdos, conectando-os ao mundo e valorizando o "lugar", que aqui entendido está relacionado não apenas ao espaço e sim a afetividade ao espaço, como nos diz Callai (2008, p. 89)

Muitas vezes sabemos coisas do mundo, admiramos paisagens maravilhosas, nos deslumbramos por cidades distantes, temos informações de acontecimentos exóticos ou interessantes de vários lugares que nos impressionam, mas não sabemos o que existe e o que está acontecendo no lugar onde vivemos.

Para isso selecionar os recursos utilizados nas aulas do estágio é de extrema importância, para compreender as necessidades dos alunos, e o que favorece a compreensão dos conteúdos. O aluno se identifica com diferentes atividades, mapas mentais, filme, resenhas, história em quadrinhos, desenhos, o que tais recursos têm em comum? É a linguagem, como nos diz Maturana, (2002, p. 37):

No entanto, se propomos a pergunta não podemos deixar de notar que os seres humanos somos o que somos ao sermos seres humanos. Quer dizer, somos conhecedores ou observadores no observar, e ao ser o que somos, o somos na linguagem. Ou seja, não podemos deixar de notar que os seres humanos somos humanos na linguagem, e ao sê-lo, o somos fazendo reflexões sobre o que nos acontece.

Em função disso as práticas desenvolvidas durante o estágio, compõe uma experiência relevante para o processo de ensino aprendizagem em Geografia, pois o geógrafo e seus alunos devem exercitar o senso crítico e observador para construir uma educação de qualidade, tão necessitada na nossa atualidade.

\section{Metodologia}

Esta pesquisa destaca-se por ter uma abordagem de pesquisa-ação a qual articula a produção de conhecimentos, a ação educativa e a participação dos envolvidos, isto é, produz conhecimentos sobre a realidade a ser estudada e, ao mesmo tempo, realiza um processo educativo, participativo, para o enfrentamento dessa mesma realidade 
(TOZONI-REIS, 2005). As turmas escolhidas para o estágio obrigatório supervisionado foram, o $6^{\circ}$ ano do ensino fundamental da Escola Municipal de Ensino Fundamental Alfredo Lenhardt, e o $1^{\circ}$ ano do ensino médio da Escola Estadual de Ensino Médio de Itaara, ambas em Itaara/RS.

O período do estágio foi de março a maio de 2016, resultando em um período avaliativo das escolas. Os conteúdos são organizados de acordo com o Projeto Político Pedagógico de cada escola, e oferecidos como embasamento ao estagiário. Dessa forma, os conteúdos que versam a Educação Ambiental estiveram fortemente vinculados à realidade do lugar pois, o município de Itaara possui uma economia baseada em dois aspectos centrais, a agricultura familiar em algumas áreas e ao turismo ambiental, onde muitos visitantes buscam experienciar uma vida afasta dos grandes centros urbanos dos municípios vizinhos. Nisso, as discussões foram sobre Planejamento Ambiental; a diferença conceitual entre preservação e conservação; planejamento urbano da cidade; áreas de preservação permanente e a ocorrência de ocupações urbanas irregulares.

O estágio na Fundação MO`Ã foi desenvolvido a partir do convenio de cooperação técnico-científico entre esta entidade e a Universidade Federal de Santa Maria (UFSM). Dentre as atividades desenvolvidas foram realizadas pesquisas na área da Reserva Particular do Patrimônio Natural Estadual MO' $\tilde{\mathrm{A}}^{4}$ (RPPN) e palestras de divulgação do Patrimônio Natural da área. Entre as ações do estágio, estão palestras sobre a conservação dos recursos, com ênfase nos recursos da região central do Rio Grande do Sul, sobre a história e objetivo da Fundação enquanto ONG ambiental atuante nesta região, assim como a apresentação do Projeto Saúde da Água ${ }^{5}$. As pesquisas na área envolveram registros e planejamento de trilhas interpretativas com o objetivo de articular ações de EA na área.

O estágio extracurricular tem por objetivo desenvolver e aprimorar os conhecimentos do professor/pesquisador, neste caso sobre Educação Ambiental, nomeadamente aqueles relacionados com a temática Água. Igualmente pretendeu-se intercambiar e promover a articulação entre o grupo de investigação PANGEA ${ }^{6}$-UFSM, CEGOT-UMinho e Laboratório da Paisagem. Durante o estágio foram promovidos ações e levantamentos, assim como discussões teóricas. As ações envolveram o levantamento

\footnotetext{
${ }^{4}$ Área que pertence a Fundação MO’ Ã, e foi instituída como Reserva Particular do Patrimônio Natural em 2015.

${ }^{5}$ Projeto da Fundação MO`Ã patrocinado pelo Programa Petrobrás socioambiental.

${ }^{6}$ Grupo de pesquisa em Patrimônio Natural, Geoconservação e Gestão da água.
} 
das atividades de EA voltadas à conservação dos recursos hídricos em Portugal, desenvolvidas por essas entidades, bem como o estudo das áreas protegidas com foco na relevância das propriedades particulares na conservação destas áreas, tendo como área de estudo a Paisagem Protegida da Montanha da Penha, localizada em Guimarães (PT). As discussões teóricas foram desenvolvidas a partir de reuniões e palestras em eventos científicos promovidas pelas entidades e executada pela pesquisadora.

\section{Resultados e Discussões}

Durante a busca por aperfeiçoamento a partir dos estágios realizados durante a vida acadêmica, foi possível desenvolver habilidades e competências que capacitaram a pesquisadora/professora para a vida profissional, principalmente com o desenvolvimento de atividades junto as turmas do estágio obrigatório supervisionado onde foi possível perceber que a utilização de recursos didáticos, quando selecionados coerentemente com o estágio de desenvolvimento dos alunos, potencializa o efeito positivo no processo de ensino-aprendizagem. Na escola Estadual de Ensino Médio de Itaara a utilização de imagens e de documentário (FIGURA 1) se fez relevante, principalmente com a proposta de um ciclo de cinema onde após cada sessão discutia-se o tema abordado. Marcondes Filho (1998) indica a utilização do vídeo como suporte a educação formal e não formal, pois, segundo ele, "desperta a curiosidade, prende a atenção, parte do concreto, mexe com a mente e o corpo do telespectador, educa mesmo sem fazer tal afirmação, procura inovar, entre outros fatores" (MARCONDES FILHO, 1998, p.106). Como método avaliativo foi proposto resenhas críticas onde o aluno pudesse expor sua opinião.

Figura 1 - Filmes e Documentários utilizados nas aulas do estágio na Escola Estadual de Ensino Médio de Itaara
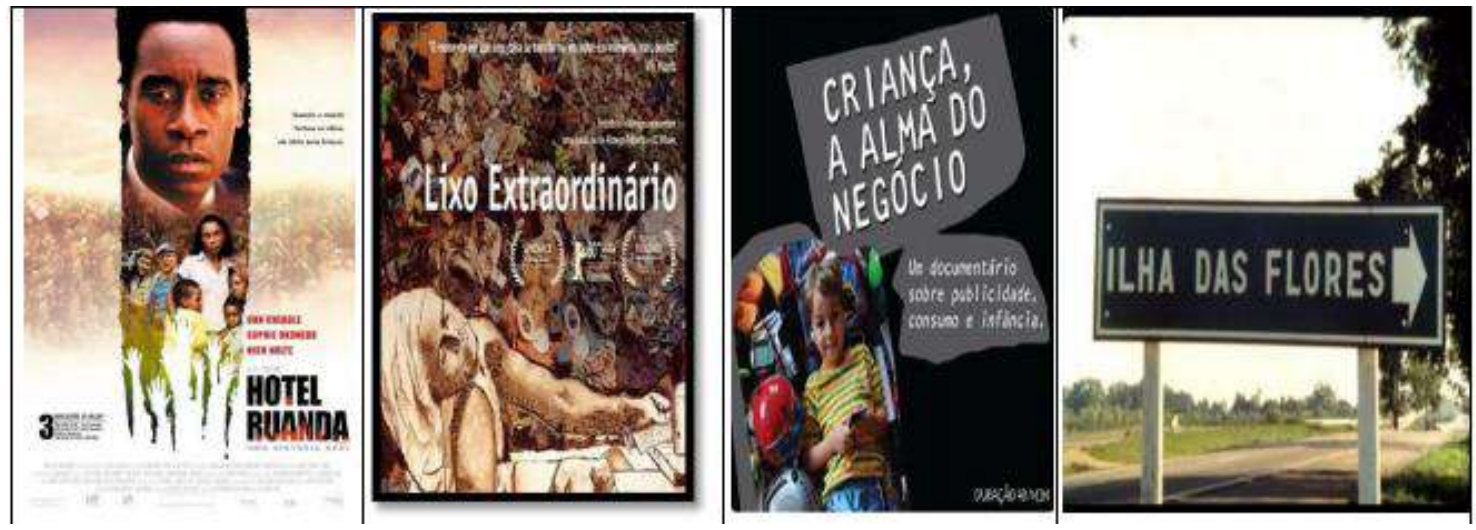

Fonte: autoras (2020) 
O tema Biodiversidade Mundial/Desenvolvimento sustentável, foi abordado pela perspectiva da Economia Verde, e utilizaram-se produtos com características biodegradáveis. Por fim ao encerrar-se as atividades construímos uma cápsula do tempo, onde os alunos escreveram uma carta para os alunos do futuro, nela foram expostos os atuais problemas ambientais, e as tecnologias existentes, para que daqui dez anos possa ser aberta e comparada com as características do futuro. O Jogo Legal ${ }^{7}$ foi aplicado durante o tema Mata Atlântica, jogo de tabuleiro que incentiva a preservação da mata Atlântica como observa-se na figura 2.

Figura 2 - Jogo educativo Fique Legal.

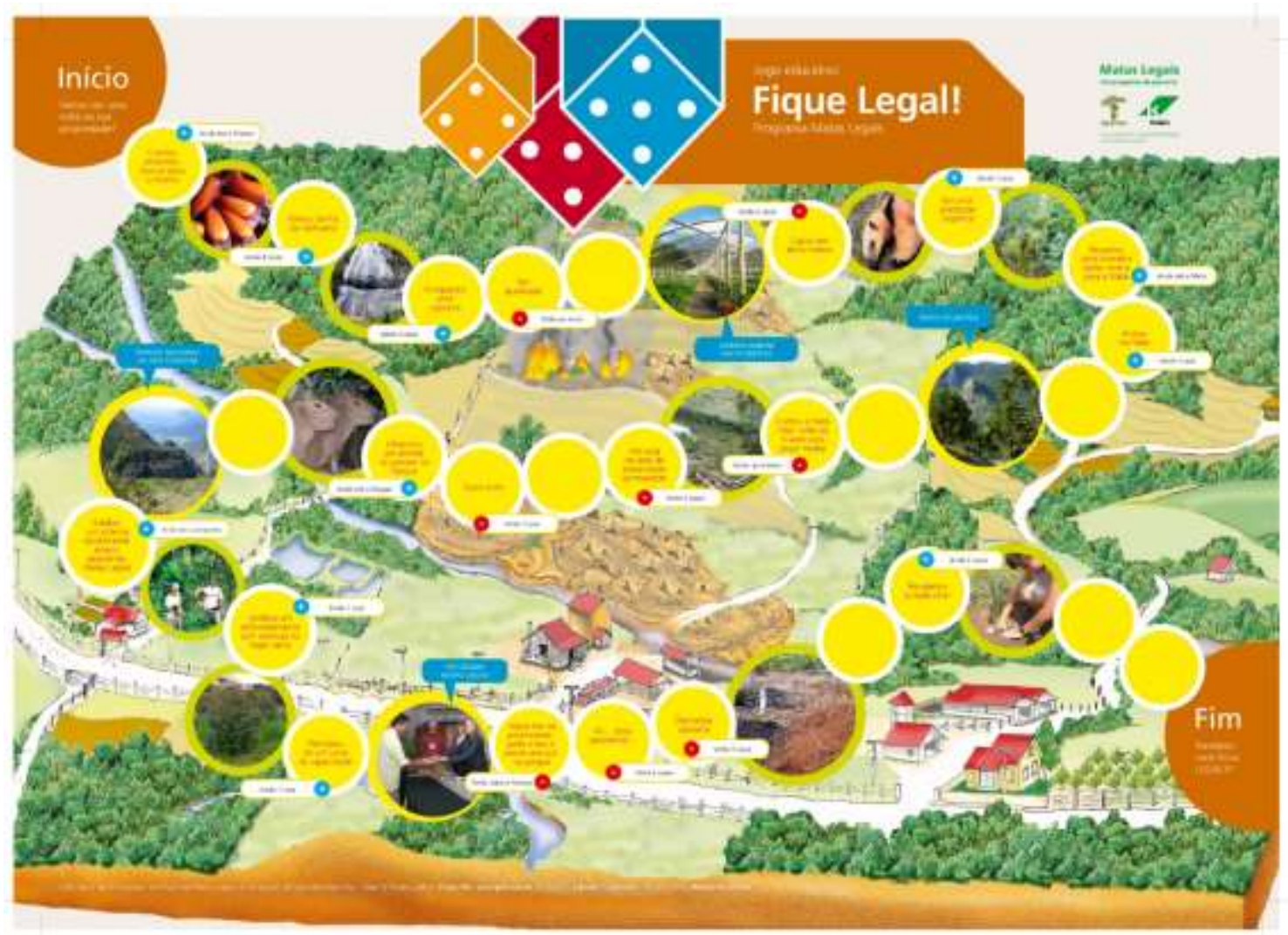

Fonte: Programa Mata Legais (2019)

Na Escola Municipal de Ensino Fundamental Alfredo Lenhardt, se fez relevante o uso de recursos didáticos em que o aluno pudesse olhar e tocar, de caráter manual. As aulas expositivas onde se construísse o raciocínio junto com o recurso, o resultado era, mais atenção e debate. Os recursos audiovisuais foram produtivos pois auxiliava os alunos a abstrair tema como Universo e a Terra. Na proposta da construção da história

\footnotetext{
${ }^{7}$ Jogo Educativo promovido pelo Programa Matas Legais (APREMAVI- https://apremavi.org.br/)
} 
em quadrinhos sobre as estações do ano, a turma do $6^{\circ}$ ano mostrou-se criativa e dedicada ao tema. Propomos a construção de história em quadrinhos como ferramentas para verificar a percepção ambiental dos alunos em relação, tomando consciência de que fazem parte de um ambiente em transformação, e que partir de um certo momento começamos a compreender que transformamos as coisas e os cenários do meio ambiente para adaptálo a nós. Fizemos isto com as tecnologias mais rudimentares que se possa imaginar, durante muitos milhares de anos. Seguimos fazendo a mesma coisa, milênios mais tarde, com tecnologias de transformação da natureza cujo poder agora nos espanta e assusta (BRANDÃO, 2005). Os saberes dos alunos são extremamente válidos, pois dão sentido real ao conhecimento adquirido em sala de aula, por que não aproveitar a experiência que têm os alunos de viver em áreas da cidade descuidadas pelo poder público para discutir, por exemplo, a poluição dos riachos e dos córregos e os baixos níveis de bem-estar das populações, os lixões e os riscos que oferecem à saúde das gentes (FREIRE, 1996). Na proposta da construção da história em quadrinhos sobre as estações do ano, a turma do $6^{\circ}$ ano mostrou-se criativa e dedicada ao tema, como pode-se observar na figura 3 . Portanto as histórias em quadrinhos são excelentes ferramentas para verificar a percepção ambiental do indivíduo em relação ao lugar onde vivem, tomando consciência de que fazem parte de um ambiente em transformação, e que partir de um certo momento começamos a compreender que transformamos as coisas e os cenários do meio ambiente para adaptá-lo a nós.

Figura 3: História em quadrinhos construídas pelos alunos do $6^{\circ}$ ano da Escola Municipal Alfredo Lenhardt

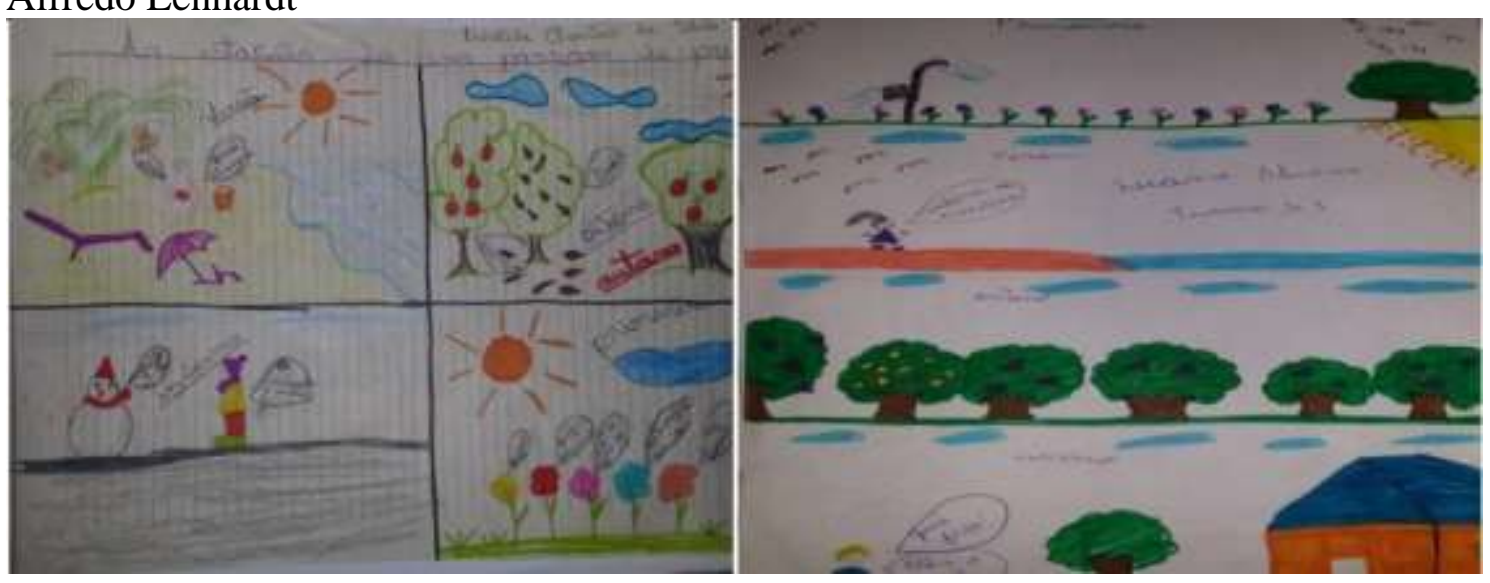

Fonte: das autoras (2019).

O estágio junto a Fundação MO’Ã foi fundamental para a o desenvolvimento de competências relacionadas a pesquisa e comunicação. Foram realizadas palestras junto a 
escolas e em eventos acadêmicos que possibilitaram a articulação e divulgação do Patrimônio Natural da Reserva Particular do Patrimônio Natural Estadual $\mathrm{MO}^{\prime} \tilde{\mathrm{A}}^{8}$. As palestras (Figura 4) abordaram atributos e a relevância da área para a conservação, foram realizadas junto as escolas onde a referente pesquisadora realizou os estágios, afim de manter o vínculo com estas instituições e continuar com o processo de ensinoaprendizagem.

Figura 4 - Palestras realizadas junto as escolas.

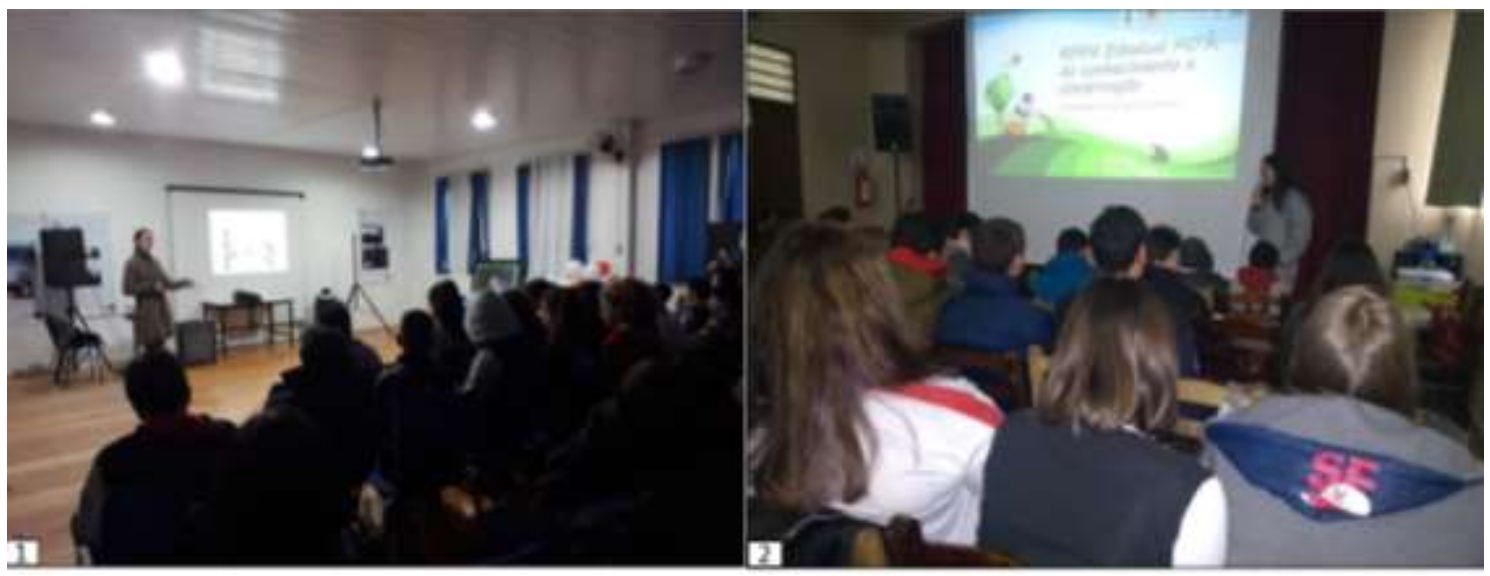

Fonte: das autoras (2019).

Este estágio foi relevante para a complementação profissional desta pesquisadora/professora, pois a preparação para as palestras para os alunos necessitou pesquisa sobre a área que seria divulgada e também uma adequada da linguagem científica para o público juvenil, considerando a atratividade da ação e o alcance do objetivo das palestras.

O estágio extracurricular realizado junto ao CEGOT e ao Laboratório da Paisagem em Guimarães (Portugal) foi relevante no âmbito de intercâmbio de conhecimento e articulação institucional, o que abriu um campo de possibilidades profissionais e desenvolvimento e aprimoramento do conhecimento da pesquisadora, que pode propor ações e realizar levantamentos relacionados ao tema de pesquisa que estava relacionada a Educação Ambiental e Áreas Protegidas. Foram realizadas saídas de campo em área protegidas como Parque Nacional Peneda-gerês, Lagoas de Bertiandos e São Pedro

\footnotetext{
${ }^{8}$ Propriedade da Fundação MO'Ã, instituída em 2015 com o objetivo de conservação da biodiversidade, compõe a Zona Núcleo da Reserva da Biosfera da Mata Atlântica e é a única RPPN instituída na região central do Rio Grande do Sul.
} 
d'arcos, Montanha da Penha onde a pesquisadora pode construir vínculos e caminhos que propiciarão novas pesquisas que aprimorarão seu conhecimento.

\section{Considerações finais}

Diante das experiências vivenciadas pelas professoras/pesquisadoras durante sua vida acadêmica, pode-se inferir que o estágio contribui de maneira significativa para a formação do profissional e que, ao propor e desenvolver o estágio junto às escolas, possibilita o processo de ensino-aprendizagem pela troca de diferentes saberes.

O estágio junto a instituições permite uma valorização do profissional e um preparo para o desenvolvimento de novas ações. E possibilita a articulação entre entidades que abre caminhos para o profissional em Geografia.

\section{Referências bibliográficas}

CAPRA, F. A teia da Vida: Uma nova compreensão cientifica dos sistemas vivos. 11 ed. SP: Editora Cultrix, 1996.

BRANDÃO, C. Aqui é onde eu moro, aqui nós vivemos: escritos para conhecer, pensar e praticar o município educador sustentável. 2 ed. Brasília: Ministério do Meio Ambiente, 2005. 181p.

BRASIL. Lei no 9.795, de 27 de abril de 1999. Dispõe sobre a educação ambiental, institui a Política Nacional de Educação Ambiental e dá outras providências. Diário Oficial da União, Brasil, DF, 27 abr. 1999. Disponível em: <http://www.planalto.gov.br/CCIVIL/leis/L9795.htm>. Acesso em: 11 março de 2020.

BRASIL. Ministério da Educação e Cultura. Secretaria de Educação Fundamental. Parâmetros Curriculares Nacionais: geografia. Brasília: MEC/SEF, 1997.

CALlai, H. C.; ZARTH, P. A. O estudo do município e o ensino de História e Geografia. Ijuí: UNIJUÍ Editora, 1988.

Estudar o lugar para compreender o mundo. In: CASTROGIOVANNI, Antônio Carlos (Org.). Ensino de Geografia: práticas e textualizações no cotidiano. $6^{\mathbf{a}}$ edição. Porto Alegre: Medição, 2008. p. 85-135.

FREIRE, P. Pedagogia da autonomia: saberes necessários à prática educativa. São Paulo: Paz e Terra, 1996.

MARCONDES FILHO, C. Televisão: a vida pelo vídeo. 7. ed. São Paulo: Moderna, 1998.

MATURANA R., H. Emoções e linguagem na educação e na política; tradução: José Fernando Campos Fortes. - Belo Horizonte: Ed. UFMG, 2002. 98 p.

TOZONI-REIS, M. F. de C. Metodologia da Pesquisa. 2. ed. Curitiba: IESDE Brasil S.A. 2005136 p. 